\title{
Usefulness of C-reactive protein testing in acute cough/respiratory tract infection: an open cluster-randomized clinical trial with C-reactive protein testing in the intervention group
}

Elena Andreeva ${ }^{{ }^{*+}}$ and Hasse Melbye ${ }^{2+}$

\begin{abstract}
Background: Point of care testing for C-reactive protein (CRP) has shown promise as a measure to reduce unnecessary antibiotic prescribing in respiratory tract infections (RTI), but its use in primary care is still controversial. We aimed to evaluate the effect of CRP testing on the prescription of antibiotics, referral for radiography, and the outcome of patients in general practice with acute cough/RTI.
\end{abstract}

Methods: An open-cluster randomized clinical trial was conducted, with CRP testing performed in the intervention group. Antibiotic prescribing and referral for radiography were the main outcome measures.

Results: A total of 179 patients were included: 101 in the intervention group and 78 in the control group. The two groups were similar in clinical characteristics. In the intervention group, the antibiotic prescribing rate was 37.6\%, which was significantly lower than that in the control group $(58.9 \%)(P=0.006)$. Referral for chest $X$-ray was also significantly lower in the intervention group (55.4\%) than in the control group (75.6\%) $(P=0.004)$. The recovery rate, as recorded by the GPs, was $92.9 \%$ and $93.6 \%$ in the intervention and control groups, respectively.

Conclusion: The study showed that CRP testing in patients with acute cough/RTI may reduce antibiotic prescribing and referral for radiography, probably without compromising recovery.

Trial registration: The trial was registered in the ClinicalTrials.gov Protocol Registration System (identification number: NCT01794819).

Keywords: Antibiotics, Respiratory tract infection, C-reactive protein, Chest radiography

\section{Background}

European medical professionals are concerned about the overuse of antibiotics and increased levels of bacterial resistance $[1,2]$. Lower respiratory tract infections (LRTI) and cough are two of the most common reasons in Europe for consulting a general practitioner (GP) [3]. Between $80 \%$ and $90 \%$ of all antibiotics are prescribed in primary care, mostly for respiratory tract infections (RTI) [1]. The frequency of antibiotic prescribing in patients with acute cough varies widely between European countries (from 28\%

\footnotetext{
* Correspondence: klmn.69@mail.ru

${ }^{\dagger}$ Equal contributors

'Department of Family Medicine, Northern State Medical University,

Arkhangelsk, the Russian Federation

Full list of author information is available at the end of the article
}

to $92 \%$ ) [4]. From a public health perspective, the major focus of the recent European Respiratory Society (ERS) guidelines for the management of LRTI is appropriate prescription of antibiotics [3].

In the Arkhangelsk region of the Russian Federation, community-acquired respiratory infections are common in general practice, constituting $40 \%$ of all consultations in adults [5]. About two-thirds of all antibiotics prescribed are for treatment of such infections. Selecting the right patients for antibiotic treatment is a major diagnostic challenge for general practitioners who are caring for patients with acute community-acquired LRTI, infectious exacerbations of asthma, or chronic obstructive pulmonary disease (COPD). The main problems in the management of patients with LRTI in primary care are, on the one hand, prescriptions of 
unnecessary antibiotics in cases of acute bronchitis where the infection is usually self-limiting, and, on the other hand, the risk of missing treatment of life-threatening pneumonia [6-8]. Differentiation between viral and bacterial LRTI would have therapeutic implications, but common clinical signs have low sensitivity and specificity for bacterial infection, and standard microbiological examinations are, in most cases, not practical in primary care [7]. Diagnostic uncertainty and an over-reliance on abnormal lung sounds on auscultation $[3,9]$ can be reasons for overprescribing antibiotics in patients with acute cough, as are patient expectation and demand [10]. Evidence-based antibiotic prescribing can be promoted in several ways, one of which could be the application of point-of-care testing (POCT) for C-reactive protein (CRP), an acute-phase protein that shows increased levels in serum during infection and tissue damage [11].

Rapid tests for CRP were introduced into general practice about 20 years ago. They are widely used in Nordic countries, mostly in cases of upper respiratory tract infection (URTI) and LRTI (from 31\% to $74 \%$ of cases) $[8,9,12,13]$. The antibiotic prescription rate is also relatively low in these countries, as shown in a European study carried out in a primary care setting $[4,14]$. Rapid CRP tests had not been used in primary care in the Arkhangelsk region before the start of this study.

In most cases, the CRP test cannot differentiate between bacterial and viral infections [15], but it does help to decrease diagnostic uncertainty [16]. Most patients consulting in general practice have CRP levels less than $20 \mathrm{mg} / \mathrm{L}[8,9]$. By avoiding the administration of antibiotics to patients with such low CRP values, unnecessary use of antibiotics may be reduced [17]. Although the strong association between CRP value and the presence of pneumonia is well documented $[6,7,18]$, evidence showing that the test can be used by GPs to improve rational use of antibiotics in LRTI is still sparse and uncertain [17,19-21]. However, the use of CRP testing in primary care has been recommended in the latest European guidelines for treatment of LRTI [3]. The Russian guidelines concerning community-acquired pneumonia recommend CRP testing as an optional investigation [22]. These guidelines indicate that chest radiography is mandatory when pneumonia is suspected [22].

A recently published systematic review and metaanalysis of primary care studies [23] pointed to a role of POCT for CRP in significantly reducing antibiotic prescribing at the index consultation for patients with RTIs.

The aim of this study was to evaluate the usefulness in Russian general practice of CRP testing in patients with acute cough/RTI. In addition to studying the effect of CRP testing on the prescription of antibiotics, we wanted to find out whether the frequency of referral for radiography could be reduced.

\section{Methods}

\section{Setting}

Eighteen general practitioners (GPs), nine from the Arkhangelsk region and nine from the Murmansk region, from both urban and rural offices, were randomized into intervention and control groups. The trial was conducted over 12 weeks (from 30 January to 30 April 2010). All registrations were made by GPs in their offices.

\section{Study population}

Patients with acute cough/LRTI (including acute bronchitis, pneumonia, and infectious exacerbations of COPD or asthma) were included. Other inclusion criteria were age 18 years or older, an illness of less than 28 days duration, first consultation for the illness episode, being seen in a physician's office, and written consent to participate. Exclusion criteria were an inability to fill out study documentation, being previously included in the study, immunocompromised status (HIV patients, immunosuppressive treatment), and ongoing treatment with oral corticosteroids.

\section{Design}

Cluster randomization was performed with GPs as units with SPSS 18.0 (IBM, Armonk, NY, USA). The rationale for using a cluster design was to ensure consecutive recruitment of patients and to avoid the situation where experience gained from the use of the test contaminated the care of control patients.

The second author generated the allocation sequence using SPSS, and the first author enrolled the clusters and made a list of clusters. Based on this list and using the allocation sequence, the first author assigned clusters to interventions.

All the GPs worked in separate outpatient departments (polyclinics), some in single GP offices and others within a GP partnership (with doctors who did not participate in this study). The sample sizes were based on a hypothesis of $20 \%$ reduction in antibiotic prescribing in the intervention group compared with the control group. Based on the chi-square statistic, the required sample size in each group was 72 participants (with a power of $90 \%$ and a risk of false positive difference less than $5 \%)$.

Two months before the trial, a baseline study without CRP testing was conducted that included 13 of the 18 participating GPs, using the same case report form (CRF) and examination. This allowed observation of prescription rates before and after the clinical trial, serving as a sensitivity analysis.

The CONSORT checklist and flow diagram are included as additional files. 


\section{The case report form (CRF)}

The CRF was similar to that used in the GRACE study (Genomics to combat Resistance against Antibiotics in Community-acquired lower respiratory tract infections in Europe [24]), describing symptoms, findings, and treatment in LRTI [4]. The GPs reported the following 15 symptoms in a questionnaire: cough, sputum production, shortness of breath, wheeze, coryza (blocked/ runny nose), fever during this illness, chest pain, muscle aches, headache, disturbed sleep, feeling generally unwell, interference with normal activities, confusion/disorientation, and diarrhoea. If increased sputum production was reported, the colour of the sputum was recorded. Symptom severity scores were calculated using the scores for 13 symptoms (similar to that computed in the GRACE study) [4]. The categories for clinicians to rate the severity of each symptom as "no problem", "mild problem", "moderate problem", or "severe problem" were scored 1, 2, 3, and 4, respectively. Scores were calculated for patients with a minimum of $85 \%$ (that is, 12 of 14 symptoms) of their symptoms recorded. This score was scaled to range between 0 and 100 so that it could be interpreted as a percentage of maximum symptom severity.

Other variables registered included sex, age and smoking status (never smoker, previous smoker and current smoker). For previous and current smokers, the average number of cigarettes per day and the number of smoking years were recorded. The pack-year criterion was calculated: one pack-year of smoking would mean that someone had smoked one pack of cigarettes (20 cigarettes) daily for one year.

The clinical examination included a chest examination and axillary temperature. The following chest findings were recorded: diminished vesicular breathing, wheezes, crackles and rhonchi.

After the clinical examination, the GPs recorded their provisional diagnosis, choosing from the following: URTI, acute bronchitis, pneumonia, COPD, asthma, non-infectious cough, and other diagnosis.

The comorbidities registered were: 1) pulmonary diseases, including COPD, asthma, tuberculosis, bronchiectasis, lung cancer, and other lung disease; 2) heart diseases, including heart failure, ischaemic heart disease, and other heart diseases (e.g., valvular lesions, cardiomyopathy); 3) diabetes; and 4) other chronic diseases.

\section{Optional examinations}

Chest radiography was accessible for all patients, and other investigations (e.g., culture of sputum, spirometry, electrocardiogram) could be ordered when necessary. All suspected pneumonia cases were confirmed by chest radiography, and films were routinely reviewed by specialists at radiology departments.

\section{CRP testing}

Before the clinical trial began, all GPs participated in two vocational training sessions concerning the CRP test, including theoretical and practical information. They were given guidelines about the interpretation of CRP results. This information included a summary of the literature on RTI and the role of CRP; paper cases of patients with different RTIs and different CRP values were discussed. They were told that antibiotics were usually not needed when the CRP value was below $20 \mathrm{mg} / \mathrm{L}$ and that a prescription could be indicated for CRP values above $50 \mathrm{mg} / \mathrm{L}$, taking into account the duration of illness [15]. However, the management, including antibiotic treatment, should be decided for each patient on an individual basis.

The CRP test was performed in the intervention group at both the first and second consultations. The Afinion test system (Axis Shield) was used, which provides results within 5 minutes and before treatment is determined. This test is based on solid-phase sandwich immunometric analysis. The measurement range in whole blood samples is $8-200 \mathrm{mg} / \mathrm{L}$. Test kits were supplied by Axis Shield.

\section{Treatment}

GPs could prescribe any treatment, including antibiotics and other drugs for the cough (e.g., cough mixture) and additional medication if deemed necessary. They were told that medication should be prescribed after the clinical examination (and after the CRP test in the intervention group), without waiting for chest radiography results.

\section{Outcome measures}

The primary outcome was the antibiotic prescribing rate. Secondary outcomes were referral to radiography and rate of recovery at the follow-up consultation after 2 weeks with the following five alternatives: "fully recovered", "almost recovered", "slightly improved", "unchanged", and "worse". Reconsultations (another consultation with the GP within 2 weeks) and complications (in need of hospitalization) were recorded.

\section{Statistical analysis}

CRP values were divided into three groups: $C R P<$ $20 \mathrm{mg} / \mathrm{L}, 20-50 \mathrm{mg} / \mathrm{L}$ and $\geq 50 \mathrm{mg} / \mathrm{L}$. Differences in the rate of prescribing antibiotics and referral to chest radiography were calculated, as was the percentage of participants who stated that they had recovered or almost recovered after 2 weeks. Differences in patient characteristics at inclusion between the intervention 
and the control group were analysed to check for recruitment bias. Changes in prescription rate between baseline and the clinical trial for each GP were analysed as part of the sensitivity analyses. The chi-square test was used to assess differences, and a P-value $<0.05$ was considered to indicate significance. As a second sensitivity analysis, the predictive value of CRP testing for antibiotic prescribing was evaluated by multivariable logistic regression, in a model including other relevant explanatory variables.

Statistical analysis was performed using SPSS 18.0.

\section{Ethics}

All patients gave informed consent. The study was approved by the local Ethics Committee of the Northern State Medical University (Arkhangelsk, Russia).

Table 1 Patient characteristics and findings in primary care patients with acute cough categorized by CRP $^{1}$ testing

\begin{tabular}{|c|c|c|c|c|c|}
\hline & \multicolumn{2}{|c|}{ Intervention group, CRP tested $(n=101)$} & \multicolumn{2}{|c|}{ Control group, CRP not tested $(n=78)$} & \multirow[t]{2}{*}{$\mathbf{P}$} \\
\hline & $\mathrm{n}$ & (\%) & $\mathrm{n}$ & (\%) & \\
\hline Male & 29 & $(28)$ & 20 & $(26)$ & 0.7 \\
\hline Current smokers & 28 & $(27)$ & 16 & $(21)$ & 0.3 \\
\hline \multicolumn{6}{|l|}{ Pre-existing illness: } \\
\hline Pulmonary diseases & 15 & $(15)$ & 14 & $(18)$ & 0.7 \\
\hline Heart diseases & 17 & $(17)$ & 3 & $(4)$ & 0.007 \\
\hline Diabetes & 5 & $(5)$ & 3 & $(4)$ & 1.0 \\
\hline Any comorbidity & 55 & $(54)$ & 39 & $(50)$ & 0.6 \\
\hline \multicolumn{6}{|l|}{ Symptoms ${ }^{2}:$} \\
\hline Cough & 60 & $(59)$ & 48 & $(62)$ & 0.9 \\
\hline Sputum & 20 & $(20)$ & 21 & $(27)$ & 0.3 \\
\hline Discoloured sputum & 56 & $(57)$ & 49 & $(63)$ & 0.4 \\
\hline Shortness of breath & 9 & (9) & 11 & $(14)$ & 0.3 \\
\hline Wheeze (reported) & 9 & (9) & 17 & $(22)$ & 0.02 \\
\hline Coryza & 19 & $(19)$ & 9 & $(12)$ & 0.2 \\
\hline Fever (history of) & 31 & $(31)$ & 26 & (33) & 0.7 \\
\hline Chest pain & 5 & (5) & 5 & (6) & 0.7 \\
\hline Muscle aches & 13 & $(13)$ & 2 & (3) & 0.01 \\
\hline Headache & 19 & (19) & 4 & (5) & 0.07 \\
\hline Disturbed sleep & 10 & $(10)$ & 4 & $(5)$ & 0.3 \\
\hline Feeling unwell & 47 & $(46)$ & 15 & (19) & 0.0001 \\
\hline Interference with daily activities & 44 & $(43)$ & 15 & $(19)$ & 0.0007 \\
\hline \multirow[t]{2}{*}{ Symptom severity ${ }^{3}$} & 44 & & 43 & & 0.4 \\
\hline & $(27-63)$ & & $(29-69)$ & & \\
\hline \multicolumn{6}{|l|}{ Findings: } \\
\hline Diminished breath sounds & 29 & $(29)$ & 30 & (38) & 0.2 \\
\hline Wheezes & 21 & $(21)$ & 19 & $(24)$ & 0.6 \\
\hline Crackles & 3 & (3) & 2 & (3) & 1.0 \\
\hline Rhonchi & 7 & (7) & 3 & (4) & 0.5 \\
\hline Any abnormal lung sound & 60 & $(59)$ & 54 & $(69)$ & 0.2 \\
\hline Temperature $\geq 37.2^{\circ} \mathrm{C}$ & 51 & $(50)$ & 49 & $(63)$ & 0.1 \\
\hline$C R P \geq 20$ and $<50 \mathrm{mg} / \mathrm{L}$ & 13 & $(13)$ & & & \\
\hline $\mathrm{CRP} \geq 50 \mathrm{mg} / \mathrm{L}$ & 7 & (7) & & & \\
\hline Perceived patient preference for antibiotics ${ }^{3}$ & 10 & $(10)$ & 18 & $(23)$ & 0.02 \\
\hline
\end{tabular}




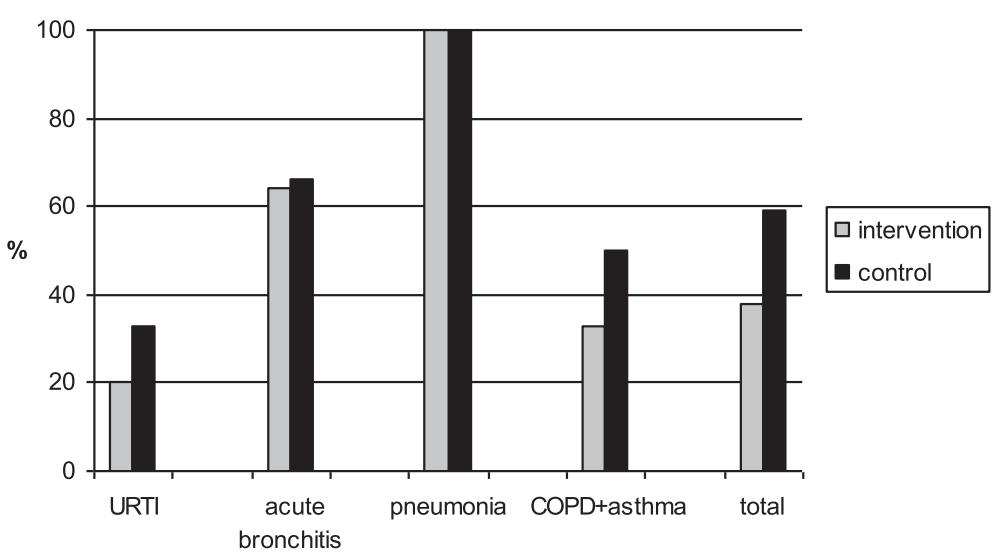

Figure 1 Antibiotic prescribing by confirmed (X-ray) diagnosis in the intervention and control groups. URTI= upper respiratory tract infections, $C O P D=$ chronic obstructive pulmonary disease.

\section{Results}

\section{Study population}

The intervention group that underwent the CRP test consisted of 101 patients recruited from four GP offices in Arkhangelsk and four GP offices in Murmansk (51 and 50 patients, respectively). Initially, 98 patients were recruited to the control group. During analysis, it became clear that there were incomplete registrations in the CRFs from two GPs, and follow-up data were frequently missing, as were patient consent forms. To assure quality, all patients from these two GPs were excluded from the analysis, and we ended up with 78 patients in the control group from four GP offices in Arkhangelsk and five GP offices in Murmansk (51 and 27 patients, respectively). The mean age was 50.8 years in both groups. Feeling unwell and experiencing limitations in daily activities were recorded more frequently in the intervention group than in the control group, whereas the severity scores were similar in the two groups. The GPs in the control group reported more frequently than those in the intervention group that the patients wanted antibiotics (Table 1). The most frequent diagnoses were URTI ( $50 \%$ and $41 \%$ in the intervention and control group, respectively) followed by acute bronchitis. Pneumonia was confirmed in $7 \%$ of the patients in the intervention group and in $17 \%$ in the control group.

\section{Antibiotic prescribing}

The rate of antibiotic prescribing on the day of inclusion was lower in the intervention group (37.6\%) than in the control group $(58.9 \%)(\mathrm{P}=0.006)$. The overall antibiotic prescribing rate during the two weeks was $40.6 \%$ in the intervention group and $71.8 \%$ in the control group $(\mathrm{P}=0.0001)$.

Antibiotics were prescribed in all cases of suspected pneumonia (Figure 1). The second most frequent reason for prescribing antibiotics was acute bronchitis $(64 \%$ and $68 \%$ in the intervention and control groups, respectively). The most frequently used antibiotic was amoxicillin, often in combination with clavulanic acid, prescribed for $73 \%$ and $72 \%$ of those given antibiotics in the intervention and control groups, respectively.

The mean CRP level in the intervention group was $11.5 \pm 24.4 \mathrm{mg} / \mathrm{L}$. Most of the patients with pneumonia had CRP values $>50 \mathrm{mg} / \mathrm{L}$, whereas none of the URTI

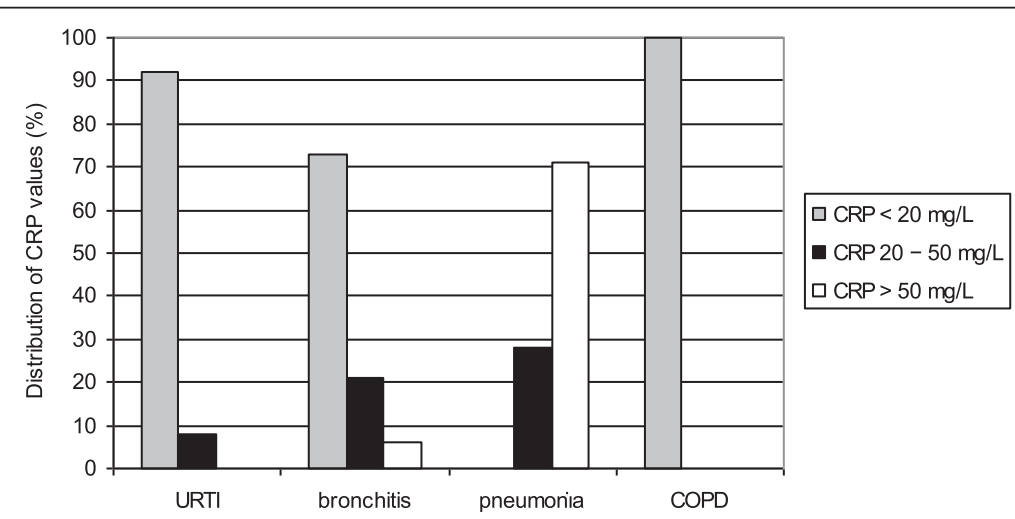

Figure 2 Distribution (\%) of CRP values by diagnosis in the intervention group. $C R P=C$-reactive protein. 


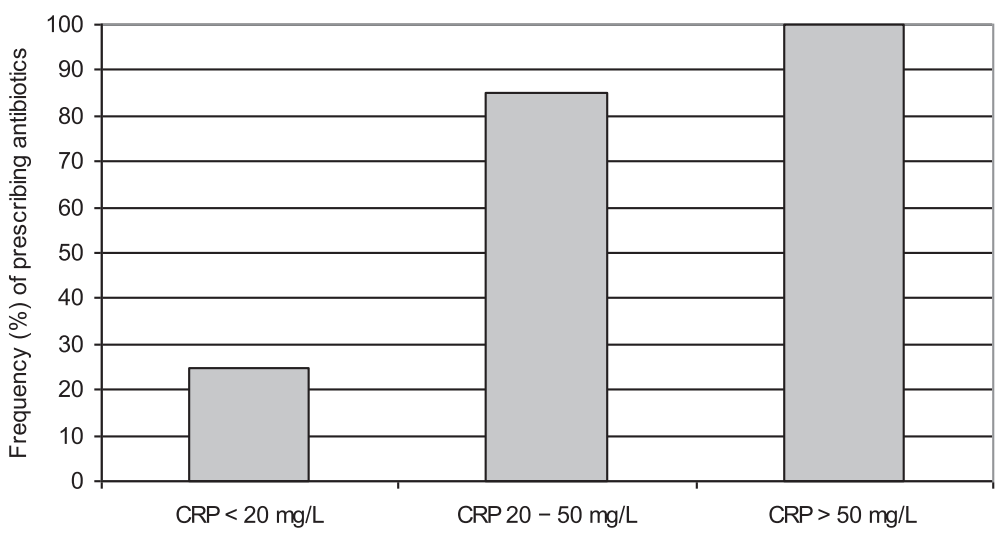

Figure 3 Frequency (\%) of prescribing antibiotics by CRP value in the intervention group. CRP =C-reactive protein.

patients had such high CRP values (Figure 2). When the CRP value was higher than $20 \mathrm{mg} / \mathrm{L}, 85 \%$ of the patients were prescribed antibiotics, compared with $28 \%$ when the CRP value was below $20 \mathrm{mg} / \mathrm{L} \quad(\mathrm{P}=0.0002)$ (Figure 3).

\section{Radiography}

The referral rate for chest radiography was significantly lower in the intervention group (55.4\%) than in the control group (76\%) $(\mathrm{P}=0.004)$. All patients with a clinical diagnosis of pneumonia were referred for radiography, whereas the lowest frequency of referral was for patients diagnosed with URTI ( $45 \%$ and $37 \%$ in the intervention and control groups, respectively).

\section{Recovery}

The frequency of reporting "almost recovered" or "fully recovered" after 2 weeks was $91.1 \%$ in the intervention group and $92.3 \%$ in the control group, but "fully recovered" was most frequently reported in the intervention group (Table 2). All patients had recovered to some degree; no patients had become worse.

\section{Sensitivity analyses}

\section{Comparisons with the baseline study}

Thirteen of the 18 GPs who took part in the clinical trial also participated in the baseline study I, which included 52 patients above the age of 18 in Arkhangelsk and 46 in Murmansk. The rate of referral for X-ray examination in the baseline study was $70.1 \%$, and the antibiotic prescribing rate was $63.3 \%$. The clinical recovery rate (the

Table 2 Clinical recovery rate in the clinical trial

\begin{tabular}{lll}
\hline & Intervention group, $\mathbf{n}(\%)$ & Control group, $\mathbf{n}(\%)$ \\
\hline Fully recovered & $55(54.4 \%)$ & $26(33.3 \%)$ \\
Almost recovered & $37(36.6 \%)$ & $46(58.9 \%)$ \\
Slightly improved & $7(6.9 \%)$ & $5(6.4 \%)$ \\
\hline
\end{tabular}

percentage of patients who were "fully recovered" or "almost recovered") was $87.7 \%$. Antibiotic prescribing rates in the baseline study and in the clinical trial by the four GPs randomized to the control group and the seven GPs randomized to the intervention group are compared in Table 3. A reduction in the prescribing rate of five of seven GPs in the intervention group was observed, whereas only one of the six GPs in the control group had reduced their prescribing rate.

\section{Evaluating the intervention by multivariable analysis}

When the effect of the intervention was analysed by multivariable logistic regression with antibiotic prescribing as outcome variable and allocation to CRP testing, URTI diagnosis, symptom score, any chest finding, any comorbidity, and perceived patient preference for antibiotic as explanatory variables, the OR of allocation to CRP testing was 0.4 (95\% confidence interval [CI] 0.18-0.89). Symptom score and perceived patient preference for antibiotics were significant positive predictors of antibiotic prescribing in this model, whereas URTI diagnosis was a significant negative predictor.

\section{Discussion}

This study demonstrated that the rate of antibiotic prescribing and referral to radiography could be reduced by the introduction of POCT for CRP. This reduction was most likely obtained without decreasing the patient recovery rate.

Some previous studies have failed to find an effect of CRP testing on antibiotic prescribing $[19,20]$. In a study from 1995 by Melbye and co-workers, the use of a rapid CRP test did not lead to a reduced rate of antibiotic prescribing in patients with LRTI [20]. Low levels of trust in the test at that time probably led to frequent prescribing, even in patients with low CRP values. A study by Gonzales and co-workers also indicated that the CRP test provided no additional value beyond clinical decision support in 
Table 3 Antibiotics prescribed in the baseline study and the clinical trial by GPs participating in both

\begin{tabular}{|c|c|c|c|c|c|c|c|}
\hline & \multicolumn{3}{|l|}{ Baseline } & \multicolumn{3}{|l|}{ Clinical trial } & \multirow[b]{2}{*}{$\mathbf{P}$} \\
\hline & $\begin{array}{l}\text { Number of } \\
\text { patients }\end{array}$ & $\begin{array}{l}\text { Patients treated } \\
\text { with antibiotics }\end{array}$ & $\begin{array}{l}\text { Antibiotic prescribing } \\
\text { rate (\%) }\end{array}$ & $\begin{array}{l}\text { Number of } \\
\text { patients }\end{array}$ & $\begin{array}{l}\text { Patients treated } \\
\text { with antibiotics }\end{array}$ & $\begin{array}{l}\text { Antibiotic prescribing } \\
\text { rate }(\%)\end{array}$ & \\
\hline \multicolumn{8}{|c|}{ Control group } \\
\hline GP A & 6 & 2 & (33) & 12 & 8 & $(66)$ & 0.3 \\
\hline GP B & 4 & 2 & (50) & 14 & 7 & $(50)$ & 1.0 \\
\hline GP C & 6 & 4 & (66) & 8 & 8 & $(100)$ & 0.2 \\
\hline GP D & 5 & 5 & $(100)$ & 8 & 8 & $(100)$ & 1.0 \\
\hline GP E & 6 & 2 & (33) & 10 & 6 & $(60)$ & 0.6 \\
\hline GP F & 7 & 6 & (86) & 10 & 7 & $(70)$ & 0.6 \\
\hline Total & 34 & 21 & (62) & 62 & 44 & (71) & 0.4 \\
\hline \multicolumn{8}{|c|}{$\begin{array}{l}\text { Intervention } \\
\text { group }\end{array}$} \\
\hline GP G & 7 & 2 & (28) & 19 & 8 & $(42)$ & 0.7 \\
\hline GP H & 6 & 5 & (83) & 10 & 4 & $(40)$ & 0.1 \\
\hline GP J & 5 & 5 & $(100)$ & 10 & 6 & $(60)$ & 0.2 \\
\hline GP K & 7 & 2 & (28) & 12 & 1 & (8) & 0.5 \\
\hline GP L & 9 & 3 & (33) & 10 & 0 & $(0)$ & 0.1 \\
\hline GP M & 7 & 7 & $(100)$ & 10 & 4 & $(40)$ & 0.08 \\
\hline GP N & 6 & 4 & (66) & 10 & 7 & (70) & 1.0 \\
\hline Total & 47 & 28 & (59) & 81 & 30 & (37) & 0.02 \\
\hline
\end{tabular}

terms of reducing antibiotic use in adults with acute cough [19]. In this study, patients with a CRP level as low as 10$20 \mathrm{mg} / \mathrm{L}$ could be treated with antibiotics according to the algorithm in the CRP group, which may be one reason for the increased prescribing rate in those tested for CRP.

In contrast to the negative findings of these two studies, Cals and co-workers showed that the use of CRP testing significantly reduced antibiotic prescribing for LRTI without decreasing the quality of care and the outcome of treatment [25]. The results of our study were similar to those of Cals et al., who also found that multifaceted interventions in addition to the use of the CRP test gave additional benefits: they found that it was valuable to provide guidance to GPs in communication skills [25]. In a recent study of 621 adult patients with acute cough or fever, $20.5 \%$ of whom had radiographically confirmed pneumonia, Steurer and co-workers concluded that pneumonia could safely be excluded in patients with CRP values below $10 \mathrm{mg} / \mathrm{L}$ and in patients without dyspnoea or daily fever with values between 11 and $50 \mathrm{mg} /$ L [21]. The CRP test has also recently been found to be useful in identifying patients with COPD exacerbations who do not need antibiotic treatment [26].

In 2012, Engel et al. published a systematic review titled "Evaluating the evidence for the implementation of C-reactive protein measurement in adult patients with suspected lower respiratory tract infection in primary care" [27]. Most of the studies that were reviewed showed limited evidence for the usefulness of CRP measurement in adult patients in primary care with suspected LRTI [27]. Only one study (Cals et al. [25]) provided firm evidence that a reduction in antibiotic prescriptions could be achieved when CRP measurement was applied [27].

The CRP test may be most useful in patients with an intermediate risk of pneumonia. Van Vugt et al., when evaluating the CRP test, concluded that "A clinical rule based on symptoms and signs to predict pneumonia in patients presenting to primary care with acute cough performed best in patients with mild or severe clinical presentation" [28]. The prevalence of pneumonia in our study was somewhat higher than in the study by van Vugt et al. This can possibly be explained by seasonal variation in morbidity (winter-spring). The geographical location of the participating GPs (northern part of Russia) and the absence of vaccination against pneumococcal infections in this area can probably also be taken into account.

In a recent meta-analysis of 13 studies in primary care including 10,005 patients, CRP testing led to significantly reduced antibiotic prescribing at the index consultation. However neither the reduction in antibiotic prescribing at any time during the 28-day follow-up period nor the increase in patient satisfaction was significant [23]. The authors emphasized that future studies are needed to analyse the confounders that lead to this heterogeneity. 


\section{Strengths and weaknesses of the study}

In the Arkhangelsk region, POC testing for CRP had not been used in primary care before this study. GPs may need time to become more experienced in the use of CRP testing and to become confident in interpreting the results. The documentation of the test's diagnostic properties and its popularity in primary care in Nordic countries may have made it easier for the GPs in the intervention group to rely on the test results.

The cluster randomization with a small number of patients in each unit made it more likely that differences between the intervention group and the control group could occur [29]. However, the uncertainty was reduced by finding a similar effect of the intervention in multivariable analysis. The results were also supported by the comparison with the baseline study. The fact that the GPs did not use CRP testing in their practice before the study made this comparison possible.

Recovery rates were evaluated by the GP and the patient together at the follow-up consultation after two weeks. GPs were aware of the purpose of the trial, and they recruited and treated patients and assessed the clinical outcome together with patients in an unblinded fashion and without standardized criteria. Because of this, the recovery data have to be interpreted with caution. Regrettably, we were missing data on the duration of illness at randomization.

\section{Clinical implications}

CRP results have been demonstrated to influence strongly the decision about whether to prescribe antibiotics for acute cough, with a steep increase in prescribing with increased CRP values $[8,9,12]$. However, when GPs think that the patient wants antibiotic treatment, they frequently prescribe antibiotics in spite of a low CRP value [9]. Communication skills are important in order to convince the patient that antibiotics are not needed. Results from CRP testing may be helpful in such an argument [9]. Using CRP testing in addition to a thorough physical examination can develop more trust between patient and doctor, and improve satisfaction with the consultation [17].

The new European guidelines for the management of adult LRTI do not indicate strong scepticism about the use of the test [3]. According to these guidelines, CRP testing can be done in patients with suspected pneumonia [3]. In cases of persistent doubt after CRP testing, a chest X-ray should be considered to confirm or reject the diagnosis [3].

\section{Conclusions}

Our study confirms that the use of POCT for CRP may reduce the rate of antibiotic prescription for acute cough/RTI. Careful use and interpretation of CRP testing in patients with RTI has the potential to benefit patients and to help GPs in the important struggle against antibiotic resistance.

\section{Competing interests}

The authors declare that they have no competing interests.

\section{Authors' contributions}

EA participated in the design of the study, led the data collection, performed the statistical analysis and drafted the manuscript. HM conceived the study and participated in its design and coordination, and helped to draft the manuscript. Both authors have read and approved the final manuscript.

\section{Acknowledgments}

We would like to thank all of the GPs from the Arkhangelsk and Murmansk regions for their help in providing clinical data.

\section{Author details}

${ }^{1}$ Department of Family Medicine, Northern State Medical University, Arkhangelsk, the Russian Federation. ${ }^{2}$ Department of Community Medicine, Faculty of Health Sciences, The Arctic University of Norway, Tromsø, Norway.

Received: 1 March 2013 Accepted: 25 April 2014

Published: 2 May 2014

\section{References}

1. Goossens H, Ferech M, Vander SR, Elseviers M: Outpatient antibiotics use in Europe and association with resistance: a cross-national database study. Lancet 2005, 365:579-587.

2. European Antimicrobial Resistance Surveillance System: EARSS annual report 2007. Bilthoven, Netherlands: National Institute for Public Health and the Environment; 2008.

3. Woodhead M: New guidelines for the management of adult lower respiratory tract infections. Eur Respir J 2011, 38:1250-1251.

4. Butler CC, Hood K, Verheij T, Little P, Melbye H, Nuttall J, Kelly MJ, Mölstad S, Godycki-Cwirko M, Almirall J, Torres A, Gillespie D, Rautakorpi U, Coenen S, Goossens $\mathrm{H}$ : Variation in antibiotic prescribing and its impact on recovery in patients with acute cough in primary care: prospective study in 13 countries. BMJ 2009, 338:b2242.

5. State Budget Institution of Health of Arkhangelsk region "Medical Information and Analytical Center": The State report on the level of health of the population of the Arkhangelsk Region in 2008. Arkhangelsk: 2009. [In Russian.] ГБУз АО "МИАЦ": Государственный доклад о состоянии здоровья населения Архангельской области в 2008.; г. Архангельск, 2009.

6. Hopstaken RM, Muris JW, Knottnerus JA, Kester AD, Rinkens PE, Dinant GJ: Contributions of symptoms, signs, erythrocyte sedimentation rate, and $\mathrm{C}$-reactive protein to a diagnosis of pneumonia in acute lower respiratory tract infection. Br J Gen Pract 2003, 53:358-364.

7. Holm A, Pedersen SS, Nexoe J, Obel N, Nielsen LP, Koldkjaer O, Pedersen C Procalcitonin versus $\mathrm{C}$-reactive protein for predicting pneumonia in adults with lower respiratory tract infection in primary care. $\mathrm{Br} J \mathrm{Gen}$ Pract 2007, 57:555-560

8. André M, Schwan A, Odenholt I, Swedish Study Group on Antibiotic Use: The use of CRP tests in patients with respiratory tract infections in primary care in Sweden can be questioned. Scand J Infect Dis 2004, 36:192-197.

9. Jakobsen KA, Melbye H, Kelly MJ, Ceynowa C, Mölstad S, Hood K, Butler CC: Influence of CRP testing and clinical findings on antibiotic prescribing in adults presenting with acute cough in primary care. Scand J Prim Health Care 2010, 28:229-236.

10. Peters S, Rowbotham S, Chisholm A, Wearden A, Moschogianis S, Cordingley L, Baker D, Hyde C, Chew-Graham C: Managing self-limiting respiratory tract infections: a qualitative study of the usefulness of the delayed prescribing strategy. Br J Gen Pract 2011, 61:e579-e589.

11. Black S, Kushner I, Samols D: C-reactive protein. J Biol Chem 2004 279:48487-48490.

12. Engström S, Mölstad S, Lindström K, Nilsson G, Borgquist L: Excessive use of rapid tests in respiratory tract infections in Swedish primary health care. Scand J Infect Dis 2004, 36:213-218.

13. Melbye $\mathrm{H}$, Stocks N: Point-of-care testing of C-reactive protein. A new path for Australian GPs? Aust Fam Physician 2006, 36:513-517.

14. Oppong R, Coast J, Hood K, Nuttall J, Smith RD, Butler CC, GRACE-01 Study Team: Resource use and costs of treating acute cough/lower respiratory tract infections in 13 European countries: results and challenges. Eur J Health Econ 2011, 12:319-329. 
15. Melbye H, Hvidsten D, Holm A, Nordbø SA, Brox J: The course of C-reactive protein response in untreated upper respiratory tract infection. $\mathrm{Br} J \mathrm{Gen}$ Pract 2004, 54:653-658

16. Coenen S: Infectious diseases in primary care; managing the interface between the person and the community. Eur J Gen Pract 2012, 18:117-121.

17. Cals JW, Schot MJ, de Jong SA, Dinant GJ, Hopstaken RM: Point-of-care C-reactive protein testing and antibiotic prescribing for respiratory tract infections: a randomized controlled trial. Ann Fam Med 2010, 8:124-133.

18. Melbye H, Straume B, Brox J: Laboratory tests for pneumonia in general practice: the diagnostic values depend on the duration of illness. Scand J Prim Health Care 1992, 10:234-240.

19. Gonzales R, Aagaard EM, Camargo CA Jr, Ma OJ, Plautz M, Maselli JH, McCulloch CE, Levin SK, Metlay JP: C-reactive protein testing does not decrease antibiotic use for acute cough illness when compared to a clinical algorithm. J Emerg Med 2011, 41:1-7.

20. Melbye H, Aaraas I, Fleten N, Kolstrup N, Mikalsen J-l: The usefulness of a rapid C-reactive protein test in the management of adults with lower respiratory tract infections. Tiddsk Nor Legeforen 1995, 115:1610-1615.

21. Steurer J, Held U, Spaar A, Bausch B, Zoller M, Hunziker R, Bachmann LM: A decision aid to rule out pneumonia and reduce unnecessary prescriptions of antibiotics in primary care patients with cough and fever. BMC Med 2011, 9:56

22. Chuchalin AG, Sinopalnikov Al, Kozlov RS, Tyurin IE, Rachina SA: Community-Acquired Pneumonia in Adults, Guideline of Diagnostics, Treatment and Prevention. CMAC 2010, 12:186-225. [In Russian.] A.Г. Чучалин, А.И. Синопальников, Р.С. Козлов, И.Е. Тюрин, С.А. Рачина: Внебольничная пневмония у взрослых: практические рекомендации по диагностике, лечению и профилактике (Пособие для врачей). Клин микробиол антимикроб химиотер 2010, 12 (3): 186-225.

23. Huang Y, Chen R, Wu T, Wei X, Guo A: Association between point-of-care CRP testing and antibiotic prescribing in respiratory tract infections: a systematic review and meta-analysis of primary care studies. $\mathrm{Br} J \mathrm{Gen}$ Pract 2013, 63:e787-e794.

24. Nuttall J, Hood K, Verheij TJM, Little P, Brugman C, Veen RER, Goossens H, Butler CC: Building an international network for a primary care research program: reflections on challenges and solutions in the set-up and delivery of a prospective observational study of acute cough in 13 European countries. BMC Family Practice 2011, 12:78.

25. Cals JWL, Butler CC, Hopstaken RM, Hood K, Dinant G-J: Effect of point of care testing for $C$ reactive protein and training in communication skills on antibiotic use in lower respiratory tract infections: cluster randomised trial. BMJ 2009, 338:b1374.

26. Llor C, Moragas A, Hernández S, Bayona C, Miravitlles M: Efficacy of antibiotic therapy for acute exacerbations of mild to moderate chronic obstructive pulmonary disease. Am J Respir Crit Care Med 2012. 186:716-723.

27. Engel MF, Paling FP, Hoepelman AIM, van der Meer V, Oosterheert JJ: Evaluating the evidence for the implementation of C-reactive protein measurement in adult patients with suspected lower respiratory tract infection in primary care: a systematic review. Fam Pract 2012, 29:383-393.

28. Van Vugt SF, Broekhuizen BD, Lammens C, Zuithoff NP, de Jong PA, Coenen S, Leven M, Butler CC, Goossens H, Little P, Verheij TJ, GRACE Consortium: Use of serum $C$ reactive protein and procalcitonin concentrations in addition to symptoms and signs to predict pneumonia in patients presenting to primary care with acute cough: diagnostic study. BMJ 2013, 346:f2450

29. Carter B: Cluster size variability and imbalance in cluster randomized controlled trials. Stat Med 2010, 29:2984-2993.

doi:10.1186/1471-2296-15-80

Cite this article as: Andreeva and Melbye: Usefulness of C-reactive protein testing in acute cough/respiratory tract infection: an open cluster-randomized clinical trial with C-reactive protein testing in the intervention group. BMC Family Practice 2014 15:80.

\section{Submit your next manuscript to BioMed Central and take full advantage of:}

- Convenient online submission

- Thorough peer review

- No space constraints or color figure charges

- Immediate publication on acceptance

- Inclusion in PubMed, CAS, Scopus and Google Scholar

- Research which is freely available for redistribution
C Biomed Central 